\title{
A Social Entrepreneurship Approach for the Development of an Active-Ageing Smartphone Application
}

\author{
George Papageorgiou \\ SYSTEMA Research Center \\ European University of Cyprus \\ Nicosia, Cyprus \\ g.papageorgiou@euc.ac.cy
}

\author{
Athanasia Ralli \\ SYSTEMA Research Center \\ European University of Cyprus \\ Nicosia, Cyprus \\ ar20185519@students.euc.ac.cy
}

\author{
Sofia A. Xergia \\ Departement of Physiotherapy \\ School of Rehabilitation Science \\ University of Patras \\ sxergia@upatras.gr
}

Received: May 28, 2021. Revised: August 3, 2021. Accepted: August 5, 2021. Published: August 11, 2021.

\begin{abstract}
Trends in the world population are shown to favor the increase market of elderly people aged 65 and over. This creates a new and promising market with many peculiarities and a variety of needs to be satisfied in terms of improving quality of life. The proposed solution to this problem which is investigated in this paper comes from technology. Especially, smart phone technology can lead to the creation of innovative products and services facilitating the elderly in their daily lives. The purpose of this study is to explore how a smart phone application (Active Ageing), could upgrade the quality of life of the elderly people and how to motivate them by making them feel safe and comfortable to go out for a walk. Further, the proposed app development takes a stakeholder's approach where the society, the state, local actors and private investors, are involved. In this way opportunities can be seized and be a deterministic factor in this new market with many economic, social and environmental benefits. At the same time, the study examines the conceptual framework of an innovative business model which will contribute to the sustainable development of the application in the Greek society by taking a social entrepreneurship approach. Going through a critical literature review in relation to Active Ageing, the benefits and risks of walking, social entrepreneurship, market research methods and smart cities, an appropriate survey instrument was developed for evaluating the potential of the envisioned Active Aging app. Elements in the survey examined key issues that concern the elderly. Specifically, market needs have been identified regarding the necessary information to create confidence, safety, enjoyment and high quality of life in a framework of sustainable mobility.
\end{abstract}

Keywords - Social Entrepreneurship, Sustainable Mobility, Active Aging, Smartphone Technology, Software Development, Market Research, Requirements Management.

\section{INTRODUCTION}

The ageing population constitute one of the main issues for the world economy. By 2050, one in three Europeans will be over 65 years old. This ratio will have a huge impact on every market and industry and all markets will have to adapt to this demographic change which will lead to new needs for products and services [1]. The Silver Economy, as it is known reflecting the gray hair of the elderly, can be considered as an opportunity for economic growth [2](European Commission, 2018) as long as the elderly remain healthy and can live independently.

In general, the term "silver economy" refers to a wide range of economic activities, from health and care products and services to areas such as mobility and environmentally assisted living, thus reaching not only parts of social entrepreneurship, but and the areas of wellness, fitness, leisure, travel, culture, communications and entertainment for the elderly.

Based on the above, it is clear that silver economy is in direct correlation with Active Ageing. Active ageing is an idea recently developed by the European Commission and the World Health Organization (WHO), which gives rise to the idea of greater activity, with a higher retirement age and work practices tailored to the employee's age. It also extends to the social commitment of older people to collectivism. The concept of active ageing was originally inspired by Robert $\mathrm{J}$. Havighurst [3], an expert in human development and ageing, in his Theory of Activity, according to which the well-being of the elderly is based on those who remain active in later life. In this respect, clearly describing what active means and supporting an active lifestyle is the key to successful ageing, [4].

Specifically, WHO considers active ageing as a lifelong process shaped by a variety of factors that work together to promote health, participation and safety in adult life. For this reason, in 2005 WHO launched the Age-Friendly Cities program and published the Global Age Friendly Cities guide: A guide that contains guidelines for promoting age-friendly conditions in cities. Elderly-friendly environments are one of the most effective approaches to tackling this major demographic change. The "Global strategy and action plan for aging and health (2016-2020)" is to make cities and settlements "inclusive" (without excluding safe), resilient and sustainable, providing universal access to safe, accessible to all green public spaces, especially for the elderly [5].

In order to promote active ageing through the "silver economy", Information and Communication Technologies (ICT) can be used, taking in advantage the multiple benefits, but also the particularities [6], of promoting sustainable mobility. Further, ICT are in direct connection with smarts cities as both can foster sustainable economic growth and a high quality of life, with wise natural resource management, through participatory governance [7]. This paper applies the proposed market research approach for the development of an "Active Ageing" app and as shown in the subsequent sections the market research approach has proven to be very useful as it provided us with valuable information about consumer needs and preferences. 


\section{RELATED STUDIES}

The development and the use of applications constitutes one of the most effective ways for reach and gain consumers and their trust [6]. It is important to note that smartphone applications is one of the most effective ways for supporting consumers daily living everywhere, while at the same time contributes to business profitability.

Note that advancements in the development and use of smartphone applications creates smart cities through the reduction of resource consumption (energy, water), reducing $\mathrm{CO} 2$ emissions and improvement in the use of existing infrastructure capacity, resulting in capital and energy savings, due to lower demand for new traditional construction projects. In addition, ICT can provide better services for sustainable mobility, and it can improve business activities and civil services in real time. This holistic approach creates many definitions of smart cities [8]. Further, ICT can support the analysis of energy demand, water, transportation [9]. It is worth mentioned that a survey by the IQVIA institute presents more than 300.000 of health-related applications exceeded worldwide[10], which shows that health-related applications constitute a main technological tool.

Physical activity including walking is extremely beneficial for health. Walking is cost effective and an easy way to improve the health of the elderly. Further, walking can undoubtedly reduce the risk of developing certain health conditions, including chronic illness and even premature death. It seems that regular physical activity, such as walking, can help prevent cardiovascular diseases, diabetes, cancer, hypertension, obesity, depression, and osteoporosis [11]. In addition, the more a person engages in physical activity, the greater the improvement in their state of health. This therefore highlights the potential for improved health in the elderly, especially those who have adopted a sedentary lifestyle instead of an active lifestyle. Staying active helps to minimize some of the problems of ageing such as increased body fat, weight loss, muscle strength and flexibility, bone loss, low metabolism and reduced reaction time (reflexes) [12], [13].

Based on the above, there is a clear need for promoting an active lifestyle for the elderly. ICT may provide effective solutions to satisfy such a need, especially, through the development of an appropriate smartphone app. However, in order to create a user's friendly smartphone application for the elderly, a social entrepreneurship approach focusing on the market should be adopted. Such an approach would include the interests of major stakeholders, including governments, municipalities and local business. This study takes a social entrepreneurship approach and applies to the case of an "Active Ageing" smartphone application as shown in the next section.

\section{A SOCIAL ENTREPRENEURSHIP APPROACH TO SMARTPHONE APPLICATION DEVELOPMENT}

Greece's international competitiveness, especially in terms of entrepreneurship and innovation, is relatively low. However, developing the market for the elderly can be a key method for the economic and social development of the country. The purpose of the proposed research is to find answers to the following questions:

- What are the key elements in the elderly market that will lead to the development of social entrepreneurship?
- In what ways can an application for a smartphone device affect the mobility of the elderly and improve their daily lives?

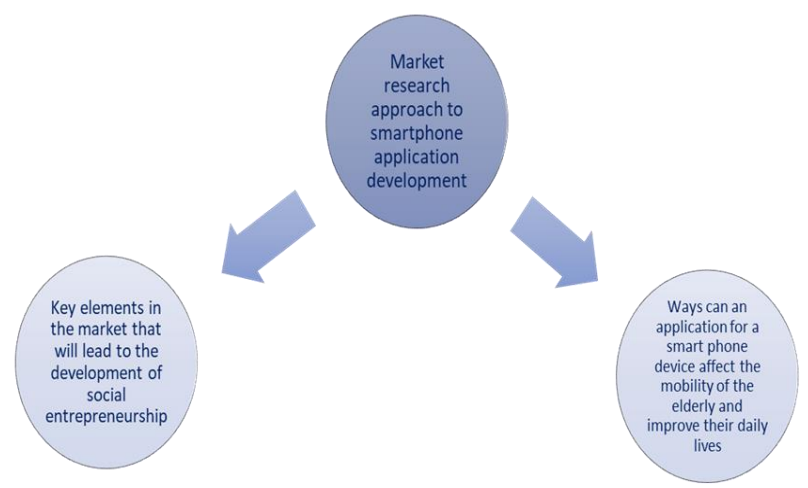

Fig. 1. The social entrepreneurship approach to smartphone application development

The social entrepreneurship approach was applied for the case of developing a smartphone application to promote "Active Ageing". Based on the key research questions a survey questionnaire was designed, which was accessible through Google Forms. The questionnaire was sent via email and a social networking platform to 164 adults, living in Athens and it was answered from $53 \%$ by males and from $47 \%$ by females between participants aged 40-71 years. It consisted of 13 closed-ended questions using a Likert scale. The initial questions referred to the demographic characteristics of the participants. The participants then had to answer questions related to the features, function and use of the application and about the safety and easy to use walks on their city. The survey also collected information about how the society, the state, local actors and private investors, can seize opportunities and be a determining factor in this new market.

After collecting the data from Google Forms, these were transferred in excel spreadsheets and then imported into the SPSS software for the statistical analysis. Initially, there was an examination of mean values and then correlation analysis was carried out between different variables. The Spearman correlation test was employed [19]. Spearman correlation is a suitable correlation method for Likert regular scale type answers, like those in the survey questionnaire. Finally, t-tests were used to compare the means of two sets of values that differ in terms of a feature.

\section{RESULTS}

The results of the survey were found to be particularly useful for the development of the new "Active Mobility" smartphone app. Correlating the relationship of the respondents with the internet and information systems as shown in Fig. 2 we see that most of the participants $34.8 \%$ describe it as good, $28 \%$ very good, $15.2 \%$ excellent and the balance $21.9 \%$ not good at all and poor. We also notice that most people aged 71 and over know how to operate information systems. 


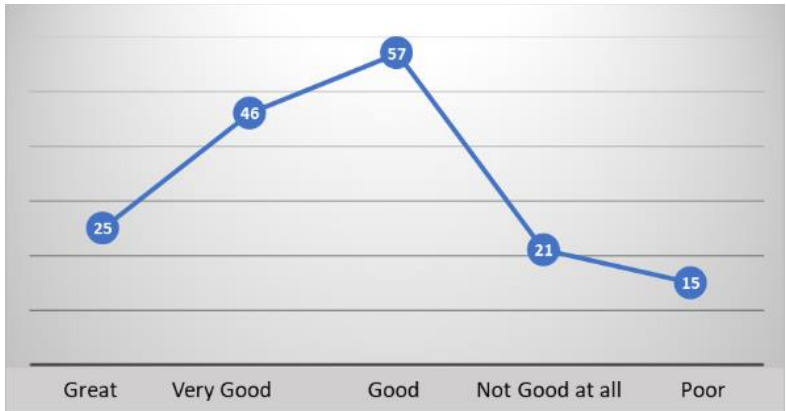

Fig. 2. Respondents' relationship with the internet

Correlating the variable of the age groups with the variable that concerns the relationship of the respondents with the technology as shown in Fig. 3, we found that there is an indication of a high correlation between them by 0.65 .

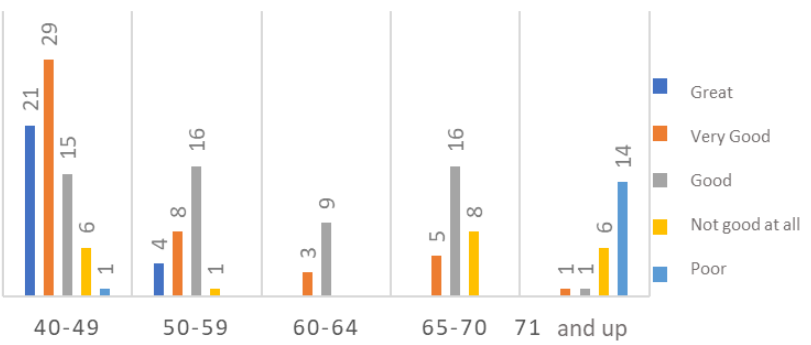

Fig. 3. Respondents' relationship with technology

In an attempt to correlate age groups 60 and older with some of the subquestions in question 4, specifically on what the participants would prefer the app to include in terms of updates and features, it was shown that almost everyone totally agrees that pager and no one disagrees as shown on Table 1.

\begin{tabular}{llll}
\hline Counting & \multicolumn{3}{l}{ Question 4.1: Possibility of 24-hour paging in case of emergency. } \\
\hline Age Group & Totally & Agree & Neither agree nor disagree \\
& agree & & \\
\multirow{2}{*}{$60-64$} & $25 \%$ & $33 \%$ & $42 \%$ \\
$65-70$ & $69 \%$ & $31 \%$ & $0 \%$ \\
71 and up & $86 \%$ & $14 \%$ & $0 \%$ \\
\hline
\end{tabular}

Table 1 . Correlation of ages over 60 with the possibility of 24-hour paging

For the correlation of the age groups that belong to the elderly regarding the safety that they believe that the application will prove them in their daily life, the results showed that $65 \%$ of the ages $65-70$ years, agree and totally agree that the creation of the application would provide them more security as shown in Fig.4 and those aged 71 and over by $68 \%$.

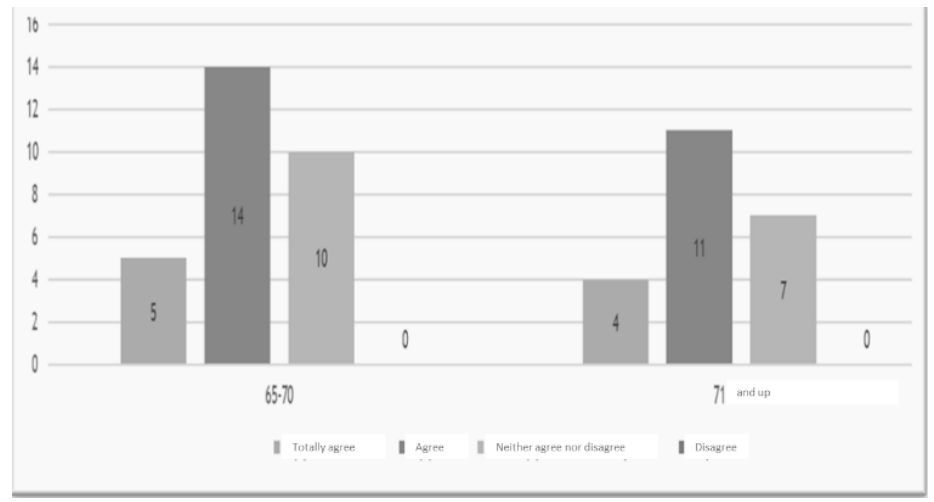

Fig. 4. Correlation of age with application safety

Concerning elderlies' motivation for walking the results showed that motivation for the $84 \%$ was the physical activity, for the $69.5 \%$ was the mental health improvement, for the $59.8 \%$ was the environmental change, for the $56 \%$ was the social contacts and for the $33.5 \%$ of the participants was entertainment as shown Table 4. In general, it is observed that there are many reasons why someone may want to go for a walk, with physical activity, improving mental health and changing the environment being the primary ones.

TABLE I. REASONS FOR AN ELDERLY PERSON TO GO FOR A WALK

\begin{tabular}{|c|c|}
\hline MOTIVATION & PERCENTAGES \\
\hline PHYSICAL ACTIVITY & $84 \%$ \\
\hline MENTAL HEALTH IMPROVEMENT & $70 \%$ \\
\hline ENVIRONMENTAL CHANGE & $60 \%$ \\
\hline SOCIAL CONTACTS & $56 \%$ \\
\hline ENTERTAINMENT & $34 \%$ \\
\hline OTHER & $3 \%$ \\
\hline
\end{tabular}

In another question that examined participants opinion about the benefits of walking, results showed that the vast majority chose the highest score, that walking is extremely important $(72 \%)$ and $20 \%$ answered that walking is very important as shown in Fig. 5 Graph 4).

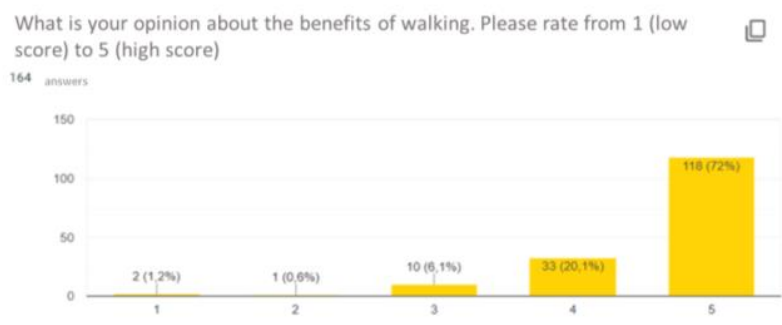

Fig. 5. Walking benefits

Further, we notice as shown in Fig.6 that there are few to very few participants $(10 \%)$ who consider the existing navigation systems are user-friendly for the elderly, most of them (49.4\%) neither disagree nor agree and the rest (34\%) think that it is not easy to use. Specifically, participants over 65 years old believe that the existing navigation systems are not user-friendly for the elderly. 
Do you believe that the existing navigation systems are user friendly for people of your age? ( $1=$ Totally agree, 2=Agree, 3=Neither disagree nor agree, $4=$ Disagree, $5=$ Totally disagree )

164. answers

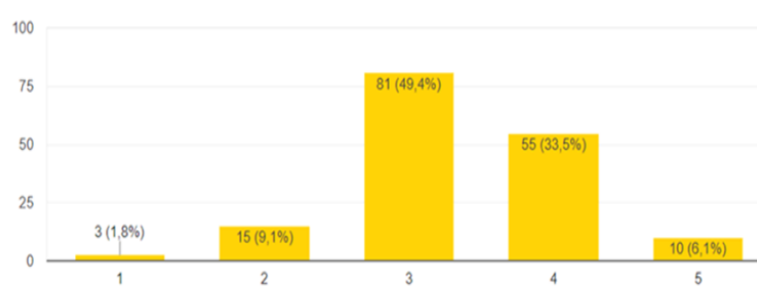

Fig. 6. Technology systems friendliness and age

In addition, the participants were asked to answer about the dangers that older people feel when they go for a walk. As shown in Fig. 7 most of the participants consider "falling over" as the major danger (144 out of 164). Many chose to be illness (119) and several answers were shared on the difficulty of remembering the way back and criminal activity (92).

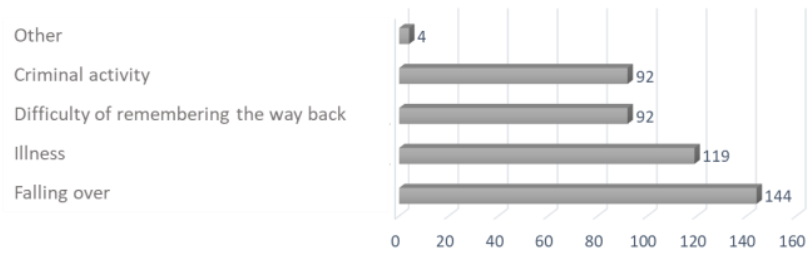

Fig. 7. Dangers that older people feel when they go for a walk

Finally, participants were asked to choose what actions they consider to be taken by the state (Government and Municipalities) to promote the development of a smartphone application that will support sustainable mobility among the elderly as shown in Fig. 8. Most of them answered that safe routes should be built (136) and free training seminars for the use of the new application should be provided (118).

\section{Other}

Advertising the new application

Safety of the routes

More parks

Free educational seminars for using the app

Free educational seminars for informational systems

Financial support

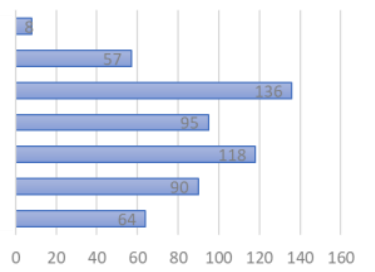

Fig. 8. Actions should be taken by the state

\section{CONCLUSION}

The development of a smartphone application for the elderly constitutes a challenging task. It is important to note that such a software development should be based on a social ideapreneurship approach focusing on the market research in order to identify real customers' needs. Based on this paper results, older people seem to be positive and open in order to use a smartphone application customized to their needs. It seems that safety and comfort constitute the main characteristics that an application should provide to elderly users. In addition, there is a significant role for the Government and Municipalities to embrace and take advantage of the potential developed application in order to promote active ageing combined with safety and pleasure. The above parameters should be included as the main requirements in the application development process.

\section{REFERENCES}

[1] [J. R. Beard, A. Officer, I. A. De Carvalho, and R. Sadana, "The World report on ageing and health: a policy framework for healthy ageing," Lancet., vol. 387, no. 10033, pp. 2145-2154, 2017.

[2] [E. Summary, "The Silver Economy."

[3] [S. Teles and O. Ribeiro, "Activity Theory," in Encyclopedia of Gerontology and Population Aging, D. Gu and M. E. Dupre, Eds. Cham: Springer International Publishing, 2019, pp. 1-8.

[4] [S. van Dyk, S. Lessenich, T. Denninger, and A. Richter, "The Many Meanings of 'Active Ageing'. Confronting Public Discourse with Older People's Stories,' Rech. Sociol. Anthropol., vol. 44, pp. 97-115, 2013.

[5] "Global strategy and action plan on ageing and health ( 2016 - 2020) Why a global strategy ?," 2020.

[6] G. Papageorgiou, A. Ioannou, A. Maimaris, and A. Ness, "A Strategic Approach for implementing A Smart Pedestrian Network (SPN) System,” Open Comput. Sci., vol. 11, no. 1, pp. 208-217, 2021.

[7] A. Caragliu, C. Del Bo, and P. Nijkamp, "Smart Cities in Europe," VU Univ. Amsterdam, Fac. Econ. Bus. Adm. Econom. Ser. Res. Memo., vol. $18,2009$.

[8] I. Greco and A. Cresta, "From SMART Cities to SMART CityRegions: Reflections and Proposals," 2017, pp. 282-295.

[9] C. Harrison and I. Donnelly, "A Theory of Smart Cities," 55th Annu. Meet. Int. Soc. Syst. Sci. 2011, 2011.

[10] H. Health, "The Growing Value of Digital Health," no. November, 2017.

[11] C. Daskalopoulou, B. Stubbs, C. Kralj, A. Koukounari, M. Prince, and A. M. Prina, "Physical activity and healthy ageing: A systematic review and meta-analysis of longitudinal cohort studies," Ageing Res. Rev., vol. 38, pp. 6-17, 2017.

[12] D. E. R. Warburton, C. W. Nicol, and S. S. D. Bredin, "Health benefits of physical activity: the evidence," 2006.

[13] R. M. Eime, J. A. Young, J. T. Harvey, M. J. Charity, and W. R. Payne, "A systematic review of the psychological and social benefits of participation in sport for children and adolescents: Informing development of a conceptual model of health through sport," Int. J. Behav. Nutr. Phys. Act., vol. 10, no. 1, p. 1, 2013.

\section{Creative Commons Attribution License 4.0 (Attribution 4.0 International, CC BY 4.0)}

This article is published under the terms of the Creative Commons Attribution License 4.0

https://creativecommons.org/licenses/by/4.0/deed.en_US 